\title{
Development and calibration of an integrative passive sampler for monitoring VCM in drinking water networks
}

\author{
L. Alembik, N. Mazzella*, T. Hemion, A. Husson, Y. Le Gat, D. Gilbert \\ INRAE Nouvelle-Aquitaine Bordeaux, 50 avenue de Verdun, 33612 Cestas, France.
}

\begin{abstract}
This paper evaluates the applicability of a new sampling device for monitoring vinyl chloride monomer (VCM) in drinking water networks. This system consists of an adsorbing cartridge filled with a strong adsorbent enclosed between two sheets of polyethylene-polyamide membrane. The passive sampler (PS) combines preconcentration on the cartridge with easy extraction by thermal desorption into a gas chromatograph (GC), coupled with a tandem mass spectrometer (MS/MS). In order to estimate the suitability of the device for this application, samplers were calibrated in a hydraulic pilot under controlled parameters. The influences of temperature, flow velocity and variation of concentration of exposure were then examined. Linear uptake was observed during a VCM exposure of 12 days and the effect of temperature on the sampling rate was evaluated. This sampling device responds to an aquatic environmental contamination and Public Health issue, both by the organic volatile contaminant monitored in this environment, and by the sampling approach, still little used in drinking water networks. It offers a complementary monitoring to the current technique, providing a more representative assessment of the temporal contamination.
\end{abstract}

\section{INTRODUCTION}

Vinyl chloride monomer (VCM) is a synthetic carcinogenic compound mainly produced for the polyvinyl chloride (PVC) industry. This contaminant can migrate into water through old PVC water pipes, which contain residual VCM remaining from their manufacture ${ }^{1,2}$

The first limitation threshold for vinyl chloride levels in drinking water was set at $0.5 \mu \mathrm{g} . \mathrm{L}^{-1}$ by the Council Directive of the European Union 98/83/EC of November 1998 on the quality of water intended for human consumption ${ }^{3}$. Until now, French Regional Health agencies (ARS) monitor VCM by grab sampling. This technique provides information on the quantity of contaminant at the moment of sampling. Depending on the frequency of spot sampling, this monitoring strategy can suffer from information gaps. Indeed, episodic contamination events can occur between two samples and, consequently, be missed.

A passive sampling approach could, therefore, be a good complementary technique to the conventional monitoring method in use. Passive sampling allows the determination of an average concentration over a given duration of exposition. The quantity of analyte can be integrated over the whole duration of exposure of the device, providing a more representative assessment of the temporal contamination.

Aquatic passive sampling has been increasingly used over the last two decades. Existing devices provide selectivity for a wide range of targeted contaminants ${ }^{4}$. Hydrophobic, metallic and, more recently, hydrophilic contaminants ${ }^{5}$ have been studied by this approach. However, few volatile organic compounds (VOCs) are sampled in natural water masses. Thus, the range of passive samplers (PS) for this type of contaminants is limited and mainly confined to air quality testing ${ }^{4,6,7,8}$.

This study aimed to develop a new device combining both aquatic and air passive sampling designs. The resulting system is based on the membrane-enclosed sorptive coating (MESCO) device $^{9,10}$, developed by Vrana et al. The receiving phase of this new sampler consists in a Radiello ${ }^{\circledR}$ cartridge, frequently used for integrative sampling of VOCs in air ${ }^{11,12}$. This device responds to the challenging needs for a waterproof system, a strong receiving phase able to adsorb VOCs and a suitable size for tap water networks. Moreover, the extraction technique used is solvent-free because thermal desorption is used for such materials. This technique avoids the issues of laborious recovery methods, solvent consumption and potential contamination.

This article presents an evaluation of the suitability of the new sampling device for the application of monitoring vinyl chloride in drinking water networks. First, samplers were calibrated in a hydraulic pilot under controlled parameters. Then, the influences of temperature, flow velocity and variation of concentration of VCM exposure were examined.

\section{THEORY}

Generally, passive samplers are based on compound diffusion from aqueous medium to a receiving phase, separated by a diffusive layer. The exchange kinetics between the passive sampler and water phase can be described by a first-order equation $^{4,13}$ :

$$
C_{S}(\mathrm{t})=C_{w} \times \frac{k_{1}}{k_{2}}\left(1-e^{-k_{2} t}\right) \quad \text { Equation } 1
$$

where $\mathrm{C}_{\mathrm{s}}(\mathrm{t})$ is the concentration of the analyte in the sampler $\left(\mu \mathrm{g} \cdot \mathrm{g}^{-1}\right)$ at exposure time $\mathrm{t}(\mathrm{h}), \mathrm{C}_{\mathrm{w}}$ represents the average concentration of spot samples in water during the deployment period $\left(\mu \mathrm{g} . \mathrm{L}^{-1}\right), \mathrm{k}_{1}$ the uptake rate constant $\left(\mathrm{L} \cdot \mathrm{g}^{-1} \cdot \mathrm{h}^{-1}\right)$ and $\mathrm{k}_{2}$ the offload rate constant $\left(\mathrm{h}^{-1}\right)$.

Two main accumulation regimes can be distinguished: integrative (kinetic) uptake, followed by an equilibrium state. This sampler is intended to be used on the integrative phase due to 
the predominance of adsorption mechanisms with microporous activated carbon sorbent ${ }^{14}$. During this regime, the concentration in the sampler can be considered as linearly proportional to the time of exposure:

$$
\begin{gathered}
C_{F}(\mathrm{t})=\frac{C_{\mathrm{s}}}{C_{\mathrm{w}}}(\mathrm{t})=k_{1} t \quad \text { Equation } 2 \\
C_{w}(\mathrm{t})=\frac{\mathrm{N}(\mathrm{t})}{R_{\mathrm{s}} t} \quad \text { Equation } 3
\end{gathered}
$$

where $\mathrm{C}_{\mathrm{F}}(\mathrm{t})$ is the concentration factor $\left(\mathrm{L}^{\mathrm{g}} \mathrm{g}^{-1}\right)$ at exposure time $\mathrm{t}(\mathrm{h}), \mathrm{N}(\mathrm{t})=\mathrm{C}_{\mathrm{s}}(\mathrm{t}) / \mathrm{m}$ corresponding to the quantity adsorbed $(\mu \mathrm{g}), \mathrm{R}_{\mathrm{s}}$ is the sampling rate $\left(\mathrm{L} \cdot \mathrm{h}^{-1}\right)$ and $\mathrm{m}$ the mass of adsorbent $(\mathrm{g})$.

\section{EXPERIMENTAL SECTION}

\section{Materials and chemicals}

The analytical standard of vinyl chloride, internal standard 1,2dichloroethane $\mathrm{d}_{4}$ and bulk sorbent Carboxen ${ }^{\circledR} 1000$ (carbon molecular sieve, mesh 60/80) were obtained from Supelco. Methanol was purchased from Biosolve (HPLC Grade). Stock solutions were prepared in methanol $\left(100 \mathrm{mg} . \mathrm{L}^{-1}\right)$ and stored at $-19^{\circ} \mathrm{C}$. Cartridges and desorption materials were provided by Radiello® and Markes $®$, respectively. Membranes were made of cut and sealed polyethylene/polyamide bags of $140-\mu \mathrm{m}$ thickness, obtained from CCM Emballage ${ }^{\circledR}$.

\section{Passive samplers \\ Sampler design.}

The passive sampler devices each consisted of a Radiello® adsorbing cartridge (stainless steel cylinder of $60 \mathrm{~mm}$ length and $4.8 \mathrm{~mm}$ diameter), packed with $350 \pm 10 \mathrm{mg}$ of Carboxen ${ }^{\circledR} 1000$ enclosed between two polyethylene/polyamide (PA/PE) membranes of $140-\mu \mathrm{m}$ thickness, $35 \mathrm{~mm}$ wide and 75 mm length (Fig. S 1).

\section{Sampler preparation.}

Just before sampling, the cartridges were introduced into empty stainless steel tubes and analysed for $5 \mathrm{~min}$ at $280^{\circ} \mathrm{C}$ at a flow rate of $80 \mathrm{ml} . \mathrm{min}^{-1}$ to check that the sorbent was clean. The total surface area of the membrane was $52.5 \pm 1.7 \mathrm{~cm}^{2}$ and the two parts were assembled with a heat sealer. After exposition, passive samplers were dried and extracted from the disposable membrane. The cartridge was introduced into a thermal desorption tube and capped with Difflok caps, obtained from Markes ${ }^{\circledR}$. Before analysis, tubes were spiked with the internal standard using a $10-\mu 1$ syringe (200 ng) inserted directly into the desorption tube.

\section{Thermal desorption method optimization.}

In order to optimize the thermal desorption (TD) analysis parameters, Radiello® cartridges were spiked with $20 \mathrm{ng}$ of VCM and $200 \mathrm{ng}$ of internal standard, using a $10-\mu \mathrm{l}$ syringe.

Desorption temperatures of $250^{\circ} \mathrm{C}, 280^{\circ} \mathrm{C}$ and $300^{\circ} \mathrm{C}$ were compared at a fixed desorption time of $5 \mathrm{~min}$ and a desorption flow of $50 \mathrm{ml} . \mathrm{min}^{-1}$, with a $10 \mathrm{ml} \cdot \mathrm{min}^{-1}$ split flow. For each temperature, triplicates were analysed. Then, helium flow rates of 30, 50, 80 and $90 \mathrm{ml} \cdot \mathrm{min}^{-1}$ were compared at a fixed temperature of $300^{\circ} \mathrm{C}$, and $5 \mathrm{~min}$ desorption time, with the same split flow. For each flow rate, triplicates were analysed. For each parameter, desorption tubes were analysed at least twice to ensure all the contaminant were desorbed.

\section{Analyte stability.}

Radiello® cartridges were spiked with $200 \mathrm{ng}$ of VCM and $200 \mathrm{ng}$ of internal standard to estimate the time of storage in the desorption tubes. The cartridges were introduced into the desorption tubes and capped with Difflok caps. After preparation, they were then stored in the thermal desorber at ambient temperature. Five standards were regularly analysed in duplicate up to 161 hours.

\section{Apparatus.}

Analyses were carried out using a TD 100-XR system (Markes ${ }^{\circledR}$ ) coupled to a Trace GC Ultra/TSQ Quantum GC system (ThermoScientific () ). All parameters and chromatographic conditions are detailed in the supplementary information (Fig. S2).

\section{Water samples}

\section{Sample preparation.}

Sample preparation was performed following the recommendations of the ISO standard 20595 on water quality describing the method of determination for selected highly volatile organic compounds in water. Considering the volatility of the VCM, sampling was carried out without turbulence in a $75-\mathrm{ml}$ glass vial and samples stored at $4{ }^{\circ} \mathrm{C}$ for a maximum of 7 days. Two $20-\mathrm{ml}$ headspace vials containing the internal standard $(100 \mu \mathrm{L}$ of a $1 \mathrm{mg} . \mathrm{L}^{-1}$ solution in methanol) were filled with $10 \mathrm{ml}$ of the sample and sealed with aluminium crimp caps with PTFE/butyl septa. The vials were immediately analysed.

\section{Validation.}

Internal calibration was performed by a 7-point linear range from 0 to $100 \mu \mathrm{g} . \mathrm{L}^{-1}$. This analytical method was validated according to the French standard NF-T $90210^{15}$.

\section{Apparatus.}

Analyses were performed by GC-MS/MS on a Trace GC Ultra/TSQ Quantum GC system (ThermoScientific $\AA)$ ). Static Headspace extraction (SHS) was performed with a Triplus Autosampler (ThermoScientific $®$ ). A TR-V1, $60 \mathrm{~m} \mathrm{x} 0.25 \mathrm{~mm}$ x $1.4 \mu \mathrm{m}$ column (ThermoScientific $\AA$ ) was chosen for the separation. All parameters and chromatographic conditions are described in the supplementary information (Fig. S 2).

\section{Calibration of passive samplers in a pilot}

Calibration was performed in a hydraulic pilot (Fig. S 3) conceived to create the best reproduction of real conditions in a drinking water network. Inside this closed/looped system, water can circulate under controlled conditions (flow, temperature). The pilot consists of three PVC pipes ( $6 \mathrm{~m}$ length, $63 \mathrm{~mm}$ outer diameter) contaminated with vinyl chloride. The contaminant diffuses through PVC into water according a zero-order kinetic. Three replicates of the calibration were carried out to study reproducibility (Cal 1, 2 and 3). The concentrations of VCM in the water at each instant $\mathrm{t}$ of the calibration are shown in boxplots Cal 1, 2 and 3 of Fig. S 9. 
In order to calibrate the samplers, the pilot setup was filled with $50 \mathrm{~L}$ of tap water and spiked with the contaminated pipes. The freshly prepared devices were exposed to an increasing concentration of VCM in the water because of the continual contamination of the pipes. Exposures were conducted at flow velocity of $76.7 \mathrm{~cm} . \mathrm{s}^{-1}$ and at $20.0 \pm 0.5^{\circ} \mathrm{C}$. Before the calibration, a blank of each cartridge and a sample of water were analysed. Grab samples were performed simultaneously to follow the VCM concentration in the water, shown as [VCM] in Figure 1 .

Finally, 8 to 12 samplers were exposed from six to 303 hours. For each point of the calibration, duplicates were analysed to estimate repeatability.

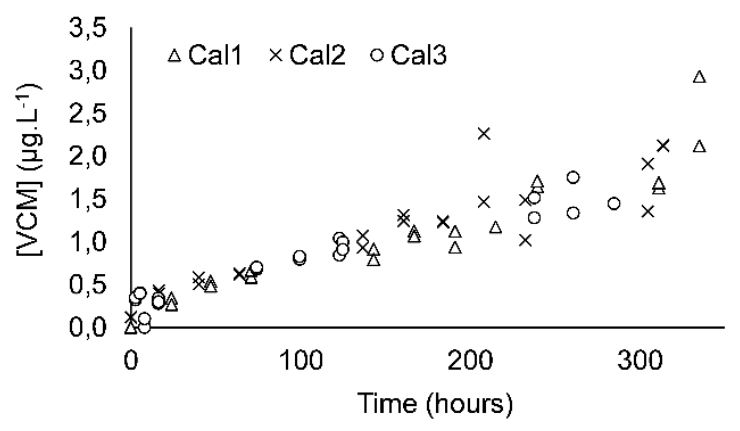

Figure 1 : Analyte concentration in water for each calibration replicate (Cal 1, 2 and 3).

\section{Pilot and static reactors parameters Validation of the normalization.}

An additional experiment was performed to estimate the influence of the variation of VCM concentration in the water $(\mathrm{Cal} 4$ on Fig. S 9). This experiment was done under the same conditions as for the calibration, except for the exposure concentration. The contaminated pipes were bypassed (for a total volume of $43 \mathrm{~L}$ ) to conduct the exposures at an average concentration of $1.12 \pm 0.30 \mu \mathrm{g} . \mathrm{L}^{-1}$. The aim of this experiment was to keep a constant concentration in the pilot. However, some probable losses of analyte occurred during the experiment, leading to a decrease of VCM concentration in the water. For this experiment, seven triplicates of samplers were exposed from 48 to 264 hours.

\section{Temperature effect on $\mathbf{R}_{\text {s. }}$.}

Two other kinetic studies were carried out in the pilot to estimate the influence of the temperature on uptake rates. Exposures were conducted at 10 and $30^{\circ} \mathrm{C}$, with a flow velocity of $76.7 \mathrm{~cm} . \mathrm{s}^{-1}$, in order to reproduce the range of temperatures in water distribution networks (WDN) as well as possible. The average concentrations of $\mathrm{VCM}$ recorded during the experiments were $4.9 \pm 1.1 \mu \mathrm{g} . \mathrm{L}^{-1}$ and $1.32 \pm 0.35 \mu \mathrm{g} . \mathrm{L}^{-1}$ for 10 and $30^{\circ} \mathrm{C}$, respectively. During these experiments, contaminated pipes were bypassed and the variation of concentration in the water did not exceed 45 and $23 \%$ of the respective initial concentrations. During these $10^{\circ} \mathrm{C}$ and $30^{\circ} \mathrm{C}$ calibrations, 18 and 24 samplers were exposed, respectively, from 41 to 144 hours, and triplicates were systematically analysed.

\section{Flow velocity effect on $\mathbf{R}_{\mathrm{s}}$.}

Two other experiments were performed both in the pilot and at the laboratory to examine the influence of the flow velocity on the passive sampler. In both cases, the quantity of water sampled was offset to keep a constant pressure and volume free of air.

In the first case (flowing conditions), samplers were exposed to $20^{\circ} \mathrm{C}$ with a flow velocity of $7.7 \mathrm{~cm} . \mathrm{s}^{-1}$ into the pilot, under a constant average VCM concentration of $2.11 \pm 0.23 \mu \mathrm{g} . \mathrm{L}^{-1}$. Contaminated pipes were bypassed and the variation of concentration in the water did not exceed $21 \%$ of the initial concentration.

In the second case (static conditions), samplers were introduced into three static pipe reactors made of three non-contaminated PVC pipes (70 $\mathrm{cm}$ length, $63 \mathrm{~mm}$ outer diameter). These reactors were filled with contaminated water from the pilot, free of air, capped and stored in a thermoregulated room at $20^{\circ} \mathrm{C}$. The constant average concentration of VCM during the experiment was $2.42 \pm 0.38 \mu \mathrm{g} . \mathrm{L}^{-1}$. Each reactor contained eight samplers exposed from 43 to 263 hours. Triplicates were analysed.

\section{RESULTS AND DISCUSSION}

\section{Optimization of TD parameters}

Thermal desorption parameters were optimized in order to transfer most of the quantity of analytes to the adsorbent after the first desorption. To ensure this, cartridges were desorbed several times, until the chromatograms obtained were empty.

\section{Desorption temperature.}

For both the VCM analyte and the selected internal standard (dichloroethane $\mathrm{d}_{4}$ ), no significant differences were observed with increasing temperature. Moreover, the areas observed after the second desorption were negligible (Fig. S 4). In order to avoid contaminants and degradation of the adsorbent, a desorption temperature of $280^{\circ} \mathrm{C}$ was chosen for the analysis.

\section{Desorption flow.}

Above $50 \mathrm{ml} \cdot \mathrm{min}^{-1}$, the entire internal standard seemed to be desorbed. The VCM peak areas were not significantly different for either desorption flow rate (Fig. S 6). To ensure the entire desorption of the dichloroethane $\mathrm{d}_{4}$, an $80 \mathrm{ml}^{\mathrm{min}}{ }^{-1}$ flow rate was chosen.

\section{Analyte stability during storage}

Since the storage recovery of volatile organic compounds can be affected over time ${ }^{16}$, the maximal duration of storage of the samples before analysis was estimated over a 6-day period. Five duplicates of spiked cartridges were stored in the thermal desorber at ambient temperature $\left(19^{\circ} \mathrm{C}\right)$ and regularly analysed. The results of this study are shown in Fig. S 8. Up to 65 hours, the quantity of VCM seemed stable. The loss of VCM peak area was $71 \%$ after 160 hours of storage. During our experiments, samples were always analysed within 8 hours following sampling step. However, this study shows that the samplers can be stored for almost three days at room temperature after preparation in the capped desorber tubes. 


\section{Water concentrations in the hydraulic pilot}

In order to evaluate the concentration of VCM in the pilot at each sampling time, grab samples of water were regularly analysed during calibration. Concentrations of VCM in the water followed the diffusion kinetic of the analyte's migration from the PVC into the water, which is represented by a zero-order kinetic (Figure 1). The concentrations increased over the calibration, with an average kinetic constant of $5.15 \pm 0.88 \mathrm{ng} . \mathrm{L}$ ${ }^{1} \cdot \mathrm{h}^{-1}$ and a relative standard deviation (RSD) of $17.2 \%$ on the slope of the kinetic. Grab sampling concentration distributions are represented as boxplots in Fig. S 9.

So as to normalize the accumulated quantities of VCM in the samplers, the average concentration of spot samples over time were calculated. The ratio of the mass of VCM in the sampler $\left(C_{s}\right)$ to the average concentration of VCM in the water $\left(C_{w}\right)$ during the same exposition period gives the concentration factor $\mathrm{C}_{\mathrm{F}}(\mathrm{t})$ in $C_{F}(\mathrm{t})=\frac{C_{\mathrm{s}}}{C_{\mathrm{W}}}(\mathrm{t})=k_{1} t \quad$ Equation 2. For each calibration standard (Cal 1, 2 and 3; Figure 1), $\mathrm{C}_{\mathrm{w}}$ was calculated by integrating the kinetic accumulation curve of VCM for each period of exposure. Boxplot representations showed the concentrations obtained for each calibration replicate (Fig. S 6). $\mathrm{C}_{\mathrm{w}}$ ranged from $0.52 \mu \mathrm{g} . \mathrm{L}^{-1}$ to $1.53 \mu \mathrm{g} . \mathrm{L}^{-1}$ during the three experiments. In comparison with the concentrations of VCM obtained with grab samples, average $C_{w}$ values were less scattered.

An additional experiment ( $\mathrm{Cal} 4$ ) was carried out to ensure the variation in concentration did not influence the uptake rate in the sampler. Contaminated pipes were isolated using a bypass. A constant concentration could not be maintained because such a slight decrease was observed, which did not exceed $52 \%$ of the initial quantity. Analyte accumulation in the samplers represented only $2 \%$ of total losses. Therefore, the decrease due to the PS was negligible compared with the losses caused by grab sampling in the pilot. Figure $\mathrm{S} 9$ shows that the dispersion of the $\mathrm{C}_{\mathrm{w}}$ in this experiment was lower than those obtained for the 3 previous calibrations.

\section{Passive sampler calibration}

\section{Uptake kinetics.}

Passive samplers were calibrated in the hydraulic pilot by exposure to concentrations of vinyl chloride in water ranging from $0.1 \mu \mathrm{g} . \mathrm{L}$ ${ }^{1}$ to $2.1 \mu \mathrm{g} . \mathrm{L}^{-1}$. Concentrations of VCM in water ([VCM]) and in the receiving phase $\left(C_{s}\right)$ were measured regularly over a 300-hour duration of exposure, at a temperature of $20^{\circ} \mathrm{C}$ and a flow velocity of $76.7 \mathrm{~cm} \cdot \mathrm{s}^{-1}$. Three experiments (i.e. Cal 1-3) were performed to estimate the reproducibility of the calibration. The uptake kinetics of VCM during the integrative regime are shown in Figure 2. The linear model was checked with an ANOVA test (Fig. S 11). The associated correlation coefficient $r$ obtained was 0.98 , which is correct for this type of sampler since the values obtained by Vrana et al. (2006) for the MESCO ranged from 0.79 to 0.99 for most of the analytes ${ }^{9}$.

\section{Sampling rates.}

Sampling rates were determined using the slope of the curve shown in Figure 2 and the mass of adsorbent in the passive samplers. The average sampling rate $R_{s}$ obtained with the three calibration replicates was about $229 \mu \mathrm{L} . \mathrm{h}^{-1}\left(2.29 \mathrm{E}-04 \mathrm{~L}^{-h^{-1}}\right)$, with an RSD of reproducibility of $9 \%$. The sampling rates of each replicate are given in Table 1 with their respective relative standard deviations (RSD).
At $19^{\circ} \mathrm{C}$, with a flow velocity of $1.3 \mathrm{~cm} . \mathrm{s}^{-1}$, Vrana et al. obtained sampling rates ranging from 158 to $983 \mu 1 . \mathrm{h}^{-1}$ for the persistent organic pollutants studied ${ }^{9}$, which are of the same order of magnitude as our values. The corresponding RSD ranged from 11 to $57 \%$ in this previous study10, making the RSD of reproducibility of our device very satisfactory.

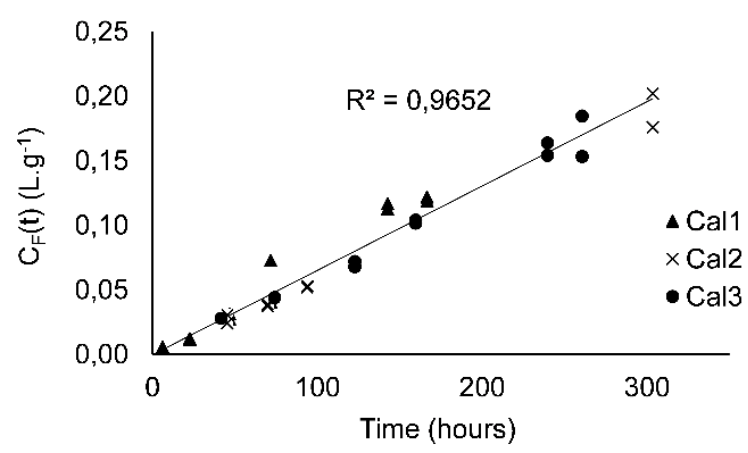

Figure 2 : Evolution of the analyte concentration factor during the integrative regime in the passive sampler at $20^{\circ} \mathrm{C}$ and $76 \mathrm{~cm} \cdot \mathrm{s}^{-1}$ for each replicate of the 3 calibrations

\section{Independence of the evolution of [VCM] on sam- pling rate}

An additional experiment was performed at $20^{\circ} \mathrm{C}$ and $76 \mathrm{~cm} \cdot \mathrm{s}^{-1}$ flow velocity. Its aim was to check whether the evolution of [VCM] during calibration had an influence on the analyte accumulation in the samplers.

The sampling rates obtained are given in Table 1 with their standard deviations. The relative standard deviation (RSD) of reproducibility calculated on the four calibration replicates was equal to $12.6 \%$. This value is satisfactory since Vrana et al. found RSD ranging from 11 to $57 \%$ for their compounds with the $\mathrm{MESCO}^{9}$, and our value corresponds to the reproducibility (calculated from the RSD of the four experiments). The ANOVA test does not show any significant effect of the variation of $[\mathrm{VCM}]$ on the sampling rate. Therefore, the next experiments were performed bypassing the contaminated pipes.

Table 1 : Sampling rate values of the three replicates of the calibrations 1 to 3 , and the validation experiment (Cal 4).

\begin{tabular}{|c|c|c|c|c|}
\hline Replicate & 1 & 2 & 3 & 4 \\
\hline Rs $\left(\boldsymbol{\mu}{\mathbf{L} . h^{-1}}^{-1}\right.$ & 270 & 223 & 237 & 282 \\
\hline RSD \% & 5.6 & 4.4 & 5.1 & 9.0 \\
\hline RSD $_{\text {repro \% }} \%$ & \multicolumn{5}{|c|}{12.6} \\
\hline RSD $_{\text {repro \% }}$ \%
\end{tabular}

\section{Influence of temperature on sampling rate}

In theory, increasing temperatures facilitate both diffusion through the different layers of the samplers and adsorption on the receiving phase. Generally, sampling rates increase with temperature, as demonstrated in several studies ${ }^{5,17,18}$. However, the effect of this parameter can be overshadowed by other factors ${ }^{19}$. Furthermore, for a single device, different sampling rate behaviours can be observed according to the compounds studied $^{18}$. 
In order to estimate the effect of temperature on the accumulation kinetic of our sampler, the uptake rates of VCM were estimated at $10^{\circ} \mathrm{C}$ and $30^{\circ} \mathrm{C}$ in addition to the previous calibrations at $20^{\circ} \mathrm{C}$ (Figure 3 ). This also allowed us to reproduce the range of temperatures in WDN. The $\mathrm{R}_{\mathrm{s}}$ and their relative standard deviations are given in Table 2 for each of these temperatures. Linear regressions were checked for each experiment. The uptake rate constants follow the Arrhenius law (Fig. 4, Fig. S 12), with an $\mathrm{R}^{2}$ value of 0.998 after linearization. The corresponding activation energy was estimated at $48.9 \pm 2.3 \mathrm{~kJ} \mathrm{~mol}^{-1}$.

Table 2: Sampling rates values at 10,20 and $30^{\circ} \mathrm{C}$, and $76 \mathrm{~cm}^{-1}$, RSD (\%) for each slope and activation energy in kJ.mol ${ }^{-1}$

\begin{tabular}{|c|c|c|c|}
\hline Temperature $\left({ }^{\circ} \mathbf{C}\right)$ & 10 & 20 & 30 \\
\hline Rs $\left(\mathbf{1 0}^{-\mathbf{4}} \mathbf{.} \mathbf{L} \cdot \mathbf{h}^{\mathbf{- 1}}\right)$ & 1.19 & 2.29 & 4.70 \\
\hline $\mathbf{R S D} \%$ & 5.8 & 8.8 & 12.7 \\
\hline Ea $\left(\mathbf{k J . m o l}{ }^{-1}\right)$ & \multicolumn{3}{|c}{48.9} \\
\hline
\end{tabular}

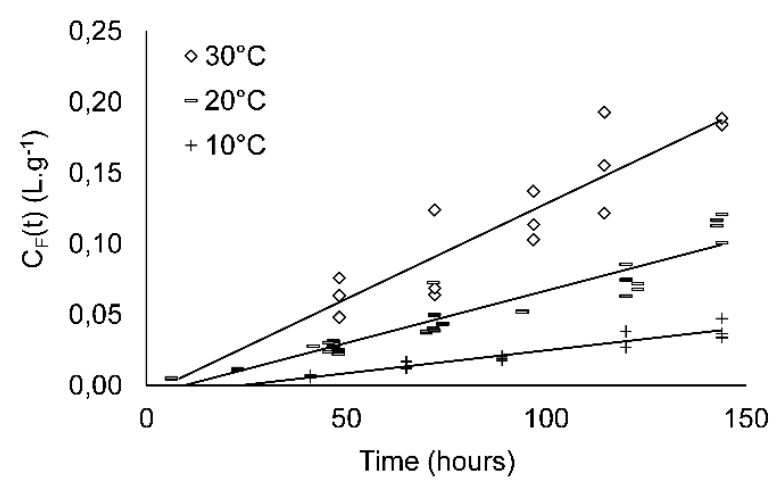

Figure 3 : Influence of temperature on VCM uptake rates at $76 \mathrm{~cm} \cdot \mathrm{s}^{-1}$

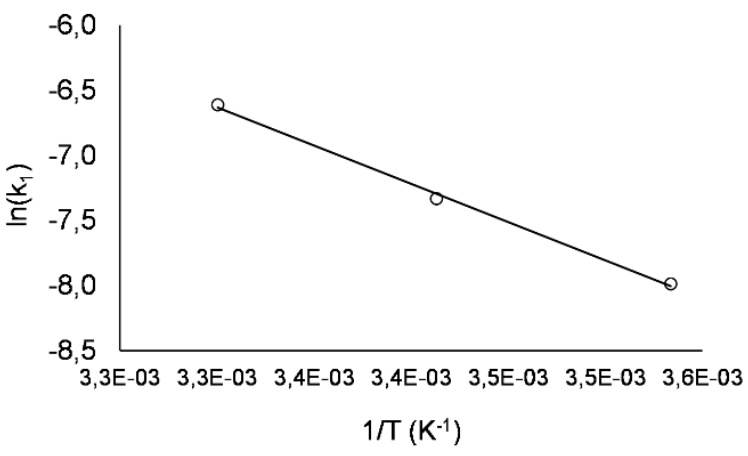

Figure 4 : Arrhenius law for VCM uptake rate constants at 10, 20 and $30^{\circ} \mathrm{C}$

Yabuki et al. (2016) estimated activation energies for many pesticides when using Polar Organic Chemical Integrative Samplers (POCIS) ${ }^{17}$. The experiment was performed from 18 to $30^{\circ} \mathrm{C}$ and the energies obtained ranged from 9.6 to $34.7 \mathrm{~kJ} . m o l^{-}$ ${ }^{1}$, making them of the same order of magnitude as our values. Vrana et al. (2006) also observed activation energies of the

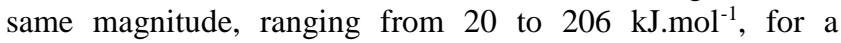

Chemcatcher sampling priority organic pollutants $\left(6^{\circ} \mathrm{C}\right.$ to $\left.18^{\circ} \mathrm{C}\right)^{20}$. However, some other studies show a twofold or lower factor increase of sampling rates for a $20^{\circ} \mathrm{C}$ variation for most of the compounds studied ${ }^{5,18}$. The increase of the sampling rate obtained in this study is twice as great as those mentioned in this literature, involving a more significant effect of temperature on VCM than on compounds usually studied in passive sampling.

\section{INFLUENCE OF FLOW VELOCITY ON SAMPLING RATE}

Several studies on POCIS report an increase of sampling rate with water flow rate ${ }^{20,21}$. In this case, the increase is due to the control that the water boundary layer (WBL) has on uptake. The decrease of WBL with an increasing flow velocity reduces the mass transfer coefficient of analytes and accelerates sampling rates. Therefore, the uptake kinetics would be sensitive to changes in flow velocity if the dominant barrier to mass transfer was the $\mathrm{WBL}^{22,23}$.

To examine the effect of flow velocity on the uptake kinetics of our device, sampling rates were compared by performing both a static experiment and one at a slower flow velocity $(\mathrm{Re}=$ 2040 , flow velocity $=7.6 \mathrm{~cm} \cdot \mathrm{s}^{-1}$ ). For each condition, sampling rate and RSD are given in Table 3 . The curves are shown in Figure 5.

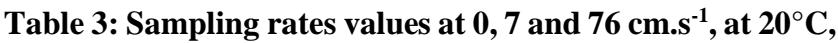
and RSD (\%) for each slope

\begin{tabular}{|c|c|c|c|}
\hline Flow velocity $\left(\mathbf{c m}^{-s^{-1}}{ }^{-1}\right)$ & 0 & 7.6 & 76 \\
\hline Rs $\left(\mathbf{1 0}^{-4} \cdot \mathbf{L} \cdot \mathbf{h}^{-1}\right)$ & 2.67 & 2.34 & 2.29 \\
\hline RSD \% & 8.6 & 7.2 & 8.8 \\
\hline
\end{tabular}

Analysis of variance did not show any significant difference between the sampling rates obtained with the different flow velocities (Fig. S 13). This behaviour can also be observed for several compounds with the $\mathrm{MESCO}^{9}$ and could be explained by the combination of the membrane thickness and the interstitial air between the cartridge and the membrane, which controls the mass transfer coefficient value more than the WBL. However, the comparison can be difficult knowing that, for most studies, the uncertainty of the flow velocity measurement is often higher than the effect of this parameter ${ }^{24}$.

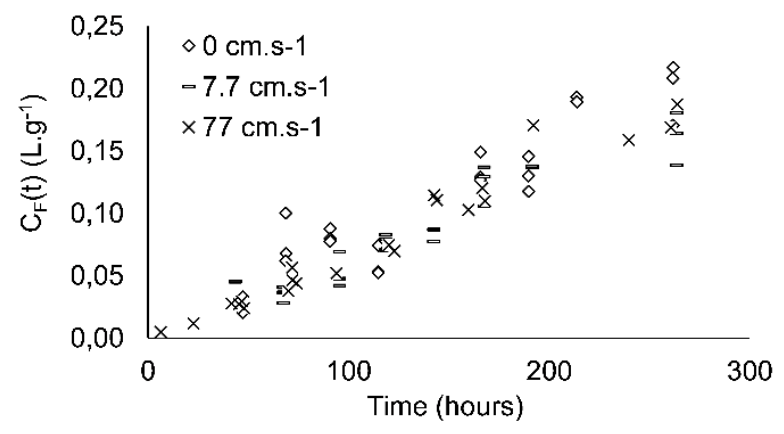

Figure 5 : Influence of flow velocity on uptake rates of VCM at $20^{\circ} \mathrm{C}$ 
A multilinear regression was performed (Fig. S 14) to evaluate the effects of temperature and flow velocity on sampling rate of our PS. A significant effect of temperature on Rs was observed, but the p-value obtained for the flow velocity parameter did not indicate a significant influence. The response surface corresponding to this model is shown in Figure 6.

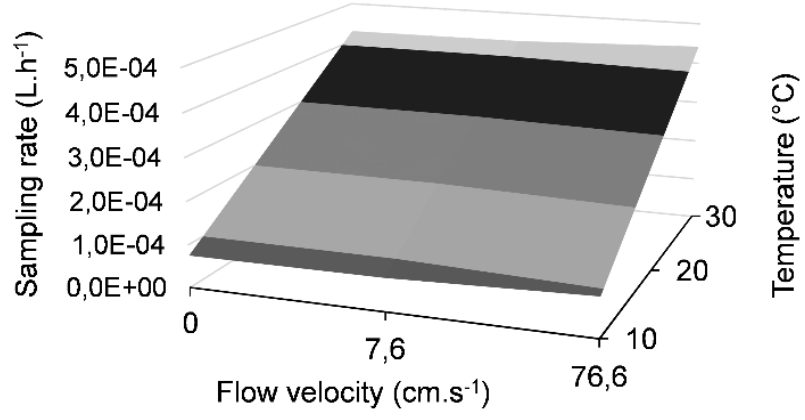

Figure 6 : Effect of temperature and flow velocity on VCM sampling rate

\section{CONCLUSION}

The passive sampling device for monitoring vinyl chloride in the drinkable water networks was developed using thermal desorption for extraction and GC-MS/MS for analysis. This PS requires only light preparation and performs direct extraction into the analysis system. The device was calibrated for 12 days in a hydraulic pilot in order to estimate the sampling rate at $20^{\circ} \mathrm{C}$ and $76 \mathrm{~cm} . \mathrm{s}^{-1}$ flow velocity and shows satisfactory reproducibility. Several experimental conditions were tested, indicating a robustness to flow velocity and an independence of the sampling rate from variation in VCM concentration in water. However, the effect of temperature on sampling rate was significant and two-fold higher than most related studies.

\section{ASSOCIATED CONTENT}

\section{Supporting Information}

Additional experimental details, including apparatus parameters and scheme of the hydraulic pilot. Additional results including thermal desorption parameters optimization, analyte stability, average concentrations in water for calibration, and $\mathrm{R}$ codes used for the statistical study. (PDF)

\section{AUTHOR INFORMATION}

\section{Corresponding Authors}

alembik.lena@gmail.com

nicolas.mazzella@inrae.fr

INRAE Nouvelle-Aquitaine Bordeaux

50 avenue de Verdun, Cestas

\section{ACKNOWLEDGMENT}

This research was supported by Agence de l'eau Adour-Garonne, Agence de l'eau Loire-Bretagne and Agence Régionale de Santé Nouvelle-Aquitaine.
The financial support was also provided by the European Regional Development Fund (ERDF) through projects "Gestion patrimoniale des réseaux d'eau" (GPRE) - Water Networks Asset Management - Aquitaine - 3547910 - $800 \mathrm{k} €$.

We thank people who extracted and supplied us with PVC pipes samples.

\section{REFERENCES}

(1) Walter, R. K.; Lin, P.-H.; Edwards, M.; Richardson, R. E. Investigation of Factors Affecting the Accumulation of Vinyl Chloride in Polyvinyl Chloride Piping Used in Drinking Water Distribution Systems. Water Res. 2011, 45 (8), 2607-2615. https://doi.org/10.1016/j.watres.2011.02.016.

(2) Berens, A. R. Prediction of Vinyl Chloride Monomer Migration from Rigid Pvc Pipe. Polym. Eng. Sci. 1976, 16 (8), 7.

(3) Council Directive 98/83/Ec of 3 November 1998 on the Quality of Water Intended for Human Consumption. Official Journal of the European Communities. 1998, pp 0032-0054.

(4) Vrana, B.; Allan, I. J.; Greenwood, R.; Mills, G. A.; Dominiak, E.; Svensson, K.; Knutsson, J.; Morrison, G. Passive Sampling Techniques for Monitoring Pollutants in Water. TrAC Trends Anal. Chem. 2005, $24 \quad$ (10), 845-868. https://doi.org/10.1016/j.trac.2005.06.006.

(5) Fauvelle, V.; Nhu-Trang, T.-T.; Feret, T.; Madarassou, K.; Randon, J.; Mazzella, N. Evaluation of Titanium Dioxide as a Binding Phase for the Passive Sampling of Glyphosate and Aminomethyl Phosphonic Acid in an Aquatic Environment. Anal. Chem. 2015, 87 (12), 6004-6009. https://doi.org/10.1021/acs.analchem.5b00194.

(6) Zabiegała, B.; Górecki, T.; Przyk, E.; Namieśnik, J. Permeation Passive Sampling as a Tool for the Evaluation of Indoor Air Quality. Atmos. Environ. 2002, 36 (17), 2907-2916. https://doi.org/10.1016/S1352-2310(02)00168-1.

(7) Küçükaçıl Artun, G.; Polat, N.; Yay, O. D.; Özden Üzmez, Ö.; Arı, A.; Tuna Tuygun, G.; Elbir, T.; Altuğ, H.; Dumanoğlu, Y.; Döğeroğlu, T.; Dawood, A.; Odabasi, M.; Gaga, E. O. An Integrative Approach for Determination of Air Pollution and Its Health Effects in a Coal Fired Power Plant Area by Passive Sampling. Atmos. Environ. 2017, 150, 331-345. https://doi.org/10.1016/j.atmosenv.2016.11.025.

(8) Hadad, K.; Safavi, A.; Tahon, R. Air Pollution Assessment in Shiraz by Passive Sampling Techniques. 2005, 29, 10.

(9) Vrana, B.; Paschke, A.; Popp, P. Calibration and Field Performance of Membrane-Enclosed Sorptive Coating for Integrative Passive Sampling of Persistent Organic Pollutants in Water. Environ. Pollut. 2006, 144 (1), 296-307. https://doi.org/10.1016/j.envpol.2005.11.046.

(10) Vrana, B.; Popp, P.; Paschke, A.; Schüürmann, G. Membrane-Enclosed Sorptive Coating. An Integrative Passive Sampler for Monitoring Organic Contaminants in Water. Anal. Chem. 2001, 73 (21), 5191-5200. https://doi.org/10.1021/ac010630z.

(11) Gonzalez, Z.; Pena, V.; Bustamonte, R.; Valdez, H.; Iii, T. W. Passive Air Study at the Ballard Pits State Superfund Site: North Pit. 2011, 22.

(12) Roukos, J.; Riffault, V.; Locoge, N.; Plaisance, H. Voc in an Urban and Industrial Harbor on the French North Sea Coast During Two Contrasted Meteorological Situations. Environ. Pollut. 2009, 157 (11), 3001-3009. https://doi.org/10.1016/j.envpol.2009.05.059.

(13) Huckins, J. N.; Petty, J. D.; Booij, K. Monitors of Organic Chemicals in the Environment: Semipermeable Membrane Devices; Springer: New York, 2006.

(14) Alvarez, D. A.; Petty, J. D.; Huckins, J. N.; Jones-Lepp, T. L.; Getting, D. T.; Goddard, J. P.; Manahan, S. E. Development of a Passive, in Situ, Integrative Sampler for Hydrophilic Organic Contaminants in Aquatic Environments. Environ. Toxicol. Chem. 2004, 23 (7), 1640. https://doi.org/10.1897/03-603.

(15) AFNOR. NF T 90-210 Water Quality - Protocol for the Initial Method Performance Assessment in a Laboratory. 2018. 
(16) Volden, J.; Thomassen, Y.; Greibrokk, T.; Thorud, S.; Molander, P. Stability of Workroom Air Volatile Organic Compounds on Solid Adsorbents for Thermal Desorption Gas Chromatography. Anal. Chim. Acta 2005, $530 \quad$ (2), 263-271. https://doi.org/10.1016/j.aca.2004.09.019.

(17) Yabuki, Y.; Nagai, T.; Inao, K.; Ono, J.; Aiko, N.; Ohtsuka, N.; Tanaka, H.; Tanimori, S. Temperature Dependence on the Pesticide Sampling Rate of Polar Organic Chemical Integrative Samplers (Pocis). Biosci. Biotechnol. Biochem. 2016, 80 (10), 2069-2075. https://doi.org/10.1080/09168451.2016.1191329.

(18) Zhang, Hao.; Davison, William. Performance Characteristics of Diffusion Gradients in Thin Films for the in Situ Measurement of Trace Metals in Aqueous Solution. Anal. Chem. 1995, 67 (19), 3391-3400. https://doi.org/10.1021/ac00115a005.

(19) Moschet, C.; Vermeirssen, E. L. M.; Singer, H.; Stamm, C.; Hollender, J. Evaluation of In-Situ Calibration of Chemcatcher Passive Samplers for 322 Micropollutants in Agricultural and Urban Affected Rivers. Water Res. 2015, 71, 306-317. https://doi.org/10.1016/j.watres.2014.12.043.

(20) Vrana, B.; Mills, G. A.; Dominiak, E.; Greenwood, R. Calibration of the Chemcatcher Passive Sampler for the Monitoring of Priority Organic Pollutants in Water. Environ. Pollut. 2006, 142 (2), 333 343. https://doi.org/10.1016/j.envpol.2005.10.033.

(21) Harman, C.; Allan, I. J.; Vermeirssen, E. L. M. Calibration and Use of the Polar Organic Chemical Integrative Sampler - a Critical Review. Environ. Toxicol. Chem. 2012, 31 (12), 2724-2738. https://doi.org/10.1002/etc.2011.

(22) Wang, L.; Gong, X.; Wang, R.; Gan, Z.; Lu, Y.; Sun, H. Application of an Immobilized Ionic Liquid for the Passive Sampling of Perfluorinated Substances in Water. J. Chromatogr. A 2017, 1515, 4553. https://doi.org/10.1016/j.chroma.2017.08.001.

(23) Chen, C.-E.; Zhang, H.; Jones, K. A Novel Passive Water Sampler for in Situ Sampling of Antibiotics. J. Environ. Monit. JEM 2012, 14, 1523-1530. https://doi.org/10.1039/c2em30091e.

(24) Booij, K.; Robinson, C. D.; Burgess, R. M.; Mayer, P.; Roberts, C. A.; Ahrens, L.; Allan, I. J.; Brant, J.; Jones, L.; Kraus, U. R.; Larsen, M. M.; Lepom, P.; Petersen, J.; Pröfrock, D.; Roose, P.; Schäfer, S.; Smedes, F.; Tixier, C.; Vorkamp, K.; Whitehouse, P. Passive Sampling in Regulatory Chemical Monitoring of Nonpolar Organic Compounds in the Aquatic Environment. Environ. Sci. Technol. 2016, 50 (1), 3-17. https://doi.org/10.1021/acs.est.5b04050. 